\title{
Construction management and technical innovation of the main project of Hong Kong-Zhuhai-Macao Bridge
}

(C) The Author(s) 2018. Published by Higher Education Press. This is an open access article under the CC BY license (http:// creativecommons.org/licenses/by/4.0)

Design Units: CCCC Highway Consultants Co., Ltd.; China Zhongtie Major Bridge Reconnaissance \& Design Institute Co., Ltd.

Construction Units: China Communications Construction Company Limited Consortium; China Railway Shanhaiguan Bridge Group Co., Ltd.; Wuhan Heavy Engineering Co., Ltd.; CCCC First Harbor Engineering Company Ltd. Consortium; Guangdong Changda Highway Engineering Co., Ltd.; China ZhongTie Major Bridge Engineering Group Co., Ltd. Consortium; Chongqing Zhixiang Paving Technology Engineering Co., Ltd.; Hunan Construction Engineering Group; China Railway Electrification Bureau Group Co., Ltd. Consortium

Supervision Units: China Railway Wuhan Bridge Engineering Consulting Supervision Co., Ltd. Consortium; China Classification Society Industrial Corp.; Wuhan Bridge and Building Works Supervision Co., Ltd.; Tiesiyuan (Hubei) Engineering Supervision Consulting Co., Ltd. Consortium; Xi' an Fangzhou Engineering Consulting Co., Ltd. Consortium; Guangdong Zhonggong Project Management Co., Ltd.; Chongqing Zhongyu Engineering Consultation and Supervision Co., Ltd. Consortium

\section{General engineering situation}

The Hong Kong-Zhuhai-Macao Bridge project spans the Lingdingyang sea area and connects the Hong Kong Special Administrative Region in the east, Zhuhai City in Guangdong Province, and Macao Special Administrative Region in the west. This project is a super-large cross-sea transportation project of Guangdong, Hong Kong, and Macao for the first time under the framework of "one

Received November 2, 2017

Yongling ZHU, Jinwen ZHANG, Xinglin GAO ( $₫)$

Hong Kong-Zhuhai-Macao Bridge Authority, zhuhai 519060, China E-mail: gx1@hzmbo.com country, two systems." The project has a total length of approximately $55 \mathrm{~km}$ and includes the following three parts: the main engineering of the sea bridge and tunnel; the ports of Hong Kong, Zhuhai, and Macao; and the lines connecting Hong Kong, Zhuhai, and Macao. The main engineering of the sea bridge and tunnel is jointly constructed and managed by the three local governments. The scope of the project originates from Zhuhai-Macao port and ends at the boundary between Guangdong and Hong Kong; it is approximately $29.6 \mathrm{~km}$ long. The bridgeisland-tunnel cluster scheme is adopted, which comprises approximately $6.7 \mathrm{~km}$ immersed tube tunnel and $22.9 \mathrm{~km}$ cross-sea bridge. An artificial island is established at both ends of the tunnel to realize the conversion between bridges and tunnels. The standard two-way six-lane expressway is constructed on the entire line. The design speed is $100 \mathrm{~km} / \mathrm{h}$, the bridge width is $33.1 \mathrm{~m}$, the tunnel width is $2 \times 14.25 \mathrm{~m}$, and the net height is $5.1 \mathrm{~m}$.

The main project of Hong Kong-Zhuhai-Macao Bridge involves white dolphin preservation, flood control, and typhoon prevention and meets the complex construction conditions of navigation, marine, and aviation. The construction management is arduous, the problems involved are numerous and new, and coordination is difficult. Thus, the construction management of the Chinese transportation industry faces a new challenge. A magnificent goal of "building a world-class bridge across the sea channel, providing the high-quality services to the users and becoming landmark buildings" is established through the Hong Kong-Zhuhai-Macao task force meeting to achieve remarkable engineering. In view of the characteristics of the project, four construction concepts of "full life cycle planning and demand-guild design; largescale, standardization, industrialization, and assembly; independent innovation and integration of global resources; green environmental protection and sustainable development" have been gradually formed to guide the engineering practice.

The "high not low" principle in the three places is 


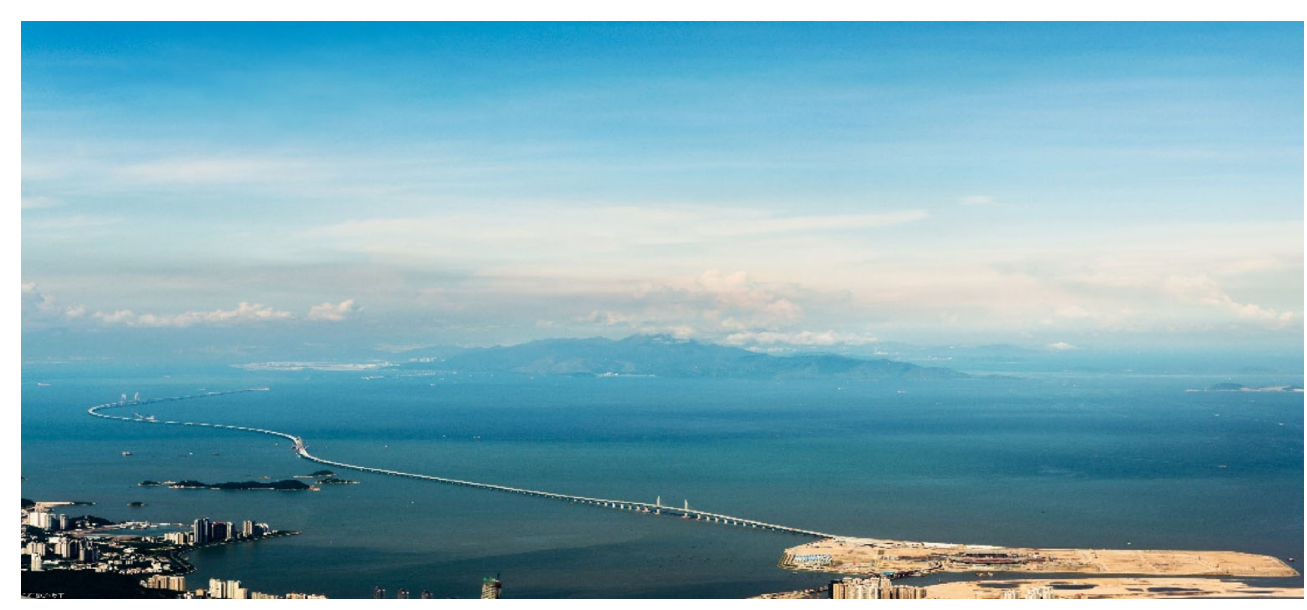

Fig. 1 A bird's eye view of Hong Kong-Zhuhai-Macao Bridge

considered in the technical norms of the project. The advantages of Hong Kong and relevant international standards are fully absorbed. Moreover, a complete technical standard system of the project is gradually established, covering all aspects of design, construction, and operation. The system not only supports the project construction but also systematically addresses the technical standards for traffic construction off the coast of China.

\section{Technical innovation of engineering con- struction}

\subsection{Island tunnel engineering}

\subsubsection{Rapid formation of artificial island}

The two artificial islands included in the main engineering are located in the open sea areas, and the entire island is established on the soft foundation of approximately $30 \mathrm{~m}$ thick. A total of 120 sets of deeply inserted steel cylinders are used to form the enclosing water seal structures of the two islands. The diameter of a single cylinder is $22 \mathrm{~m}$, the height is $40-50 \mathrm{~m}$, and the weight is approximately $500 \mathrm{t}$. The two artificial islands of $100000 \mathrm{~m}^{2}$ are completed in 207 days by adopting innovative technology, thereby achieving the construction target of "formation of the island within the same year of groundbreaking." This construction is the fastest among offshore artificial islands in China thus far. The construction efficiency is increased by nearly five times, the seabed excavation amount is reduced greatly, and the pollution to the sea is also minimized compared with the traditional riprap-cofferdam method.

\subsubsection{Factory manufacture of tunnel pipe joint}

The submarine tunnel is the first super-large immersed

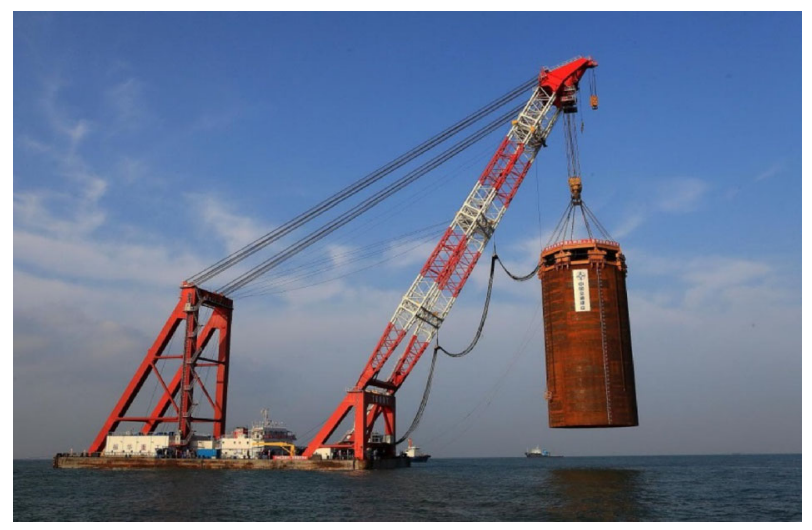

Fig. 2 Rapid formation of deeply inserted steel cylinder for the artificial island

tube tunnel constructed in the open sea. The length of the immersed tube section in the sea reaches $5664 \mathrm{~m}$ and is composed of 33 sections. The length of the standard tube is $180 \mathrm{~m}$, the weight is approximately $80000 \mathrm{t}$, and the maximum working water depth is $46 \mathrm{~m}$. The designed service life of 120 years introduces high requirement for the self-waterproof and concrete durability of the immersed tube structure. For the first time, the country used an immersed tube section that is entirely "factory manufactured." Compared with the traditional "dry docking method," the factory method can form a pipeline production mode, achieve 365 days of uninterrupted flow production, raise the efficiency and quality of the pipe section precast, and represent future technological trend of large-scale production of large components.

2.1.3 Floating transportation and installation of immersed tube

A standard tube section weighs approximately $80000 \mathrm{t}$, 


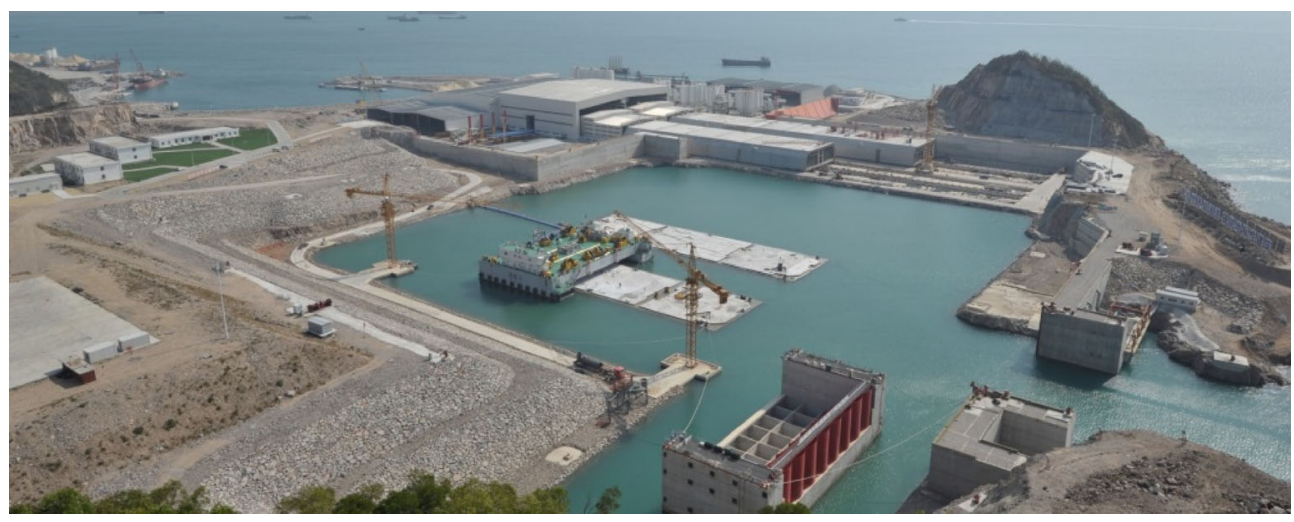

Fig. 3 Panorama of immersed tube precast plant

which is similar with an aircraft carrier. The floating route is located in the busiest navigable waters of the Lingdingyang Bay, which is extremely difficult to operate. To this end, we cooperate with the professional team of marine environment prediction to perform small regional hydrological and meteorological forecasting, thereby providing accurate wind-wave flow conditions for the decisions in every stage of floating and immersing. We jointly work with the maritime department to implement the temporary maritime traffic control and escort and use 11 high-powered full-turn tugs for collaboration. Numerous independent studies and development of dedicated pipe joint sinking control and support facilities have been conducted, including the pipe ballast system, deep water measurement and control system, tension control system, internal control system, operation window management system, back-silting monitoring, and early warning system, which satisfies the requirement of the docking accuracy in $46 \mathrm{~m}$ depth.

\subsubsection{Final joint installation of tunnel}

The total weight of the final joint of the immersed tunnel is $6120 \mathrm{t}$ with a length of $9.6 \mathrm{~m}$ bottom plate and $12 \mathrm{~m}$ top plate. The final joint is located between the E29 and E30 immersed pipes. The "integral installation of active pushing and sealing water" mode of new joint structure and method are innovatively adopted. For the first time in China, the immersed tube structure of "sandwich" steel shell concrete and the new method of "high fluidity concrete" are used. Moreover, the world'first use " $\mathrm{M}+$ LIP + GINA" waterproof belt combined with a push system is used for temporary water stopping in immersed tube works. Meanwhile, the final joint construction is affected by the "gear phenomenon" of the deep slot and the "gap effect" in Longkou. The current is exceptionally complex, and the installation space is extremely limited; thus, the installation work appears as "threading a needle" in the waves. From design to construction, the final joint engineering lasted for three years. More than 50 project studies and test exercises were completed, and the final precision installation is ultimately achieved. For the first time, the final joint engineering is performed watertight in deep complex water environment.

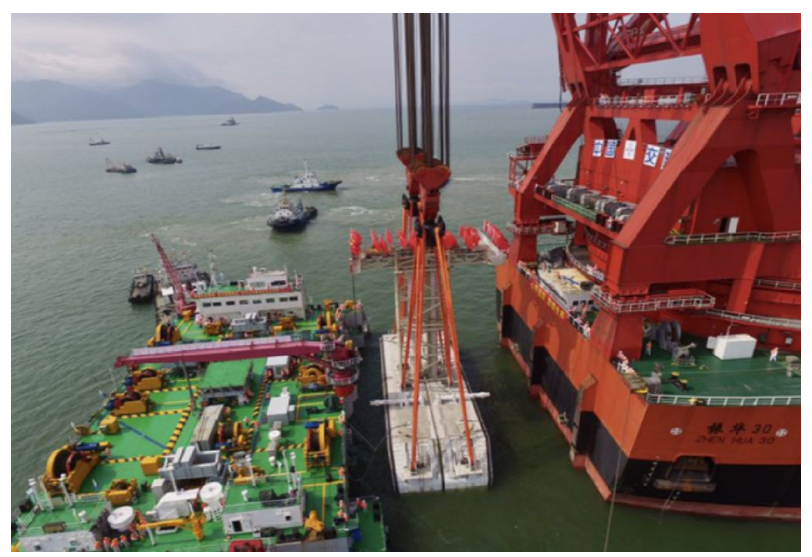

Fig. 4 Final joint installation of the immersed tunnel

\subsection{Bridge engineering}

\subsubsection{Automatic manufacture of bridge steel structure}

The steel consumption of the bridge steel structure in the main engineering consumes 42.5 million tons, which is the first in China. The idea of industrial lean manufacturing has been pioneered to ensure the quality and duration of the construction. The manufacturing and management concepts of "minimizing the number of plate unit personnel, using factory full automatic production line," "optimizing the assembly plant personnel and changing site construction to factory manufacturing" are proposed. Advanced production line and equipment are used to replace and eliminate the backward production capacity, a new automatic production line is established, and 100\% 


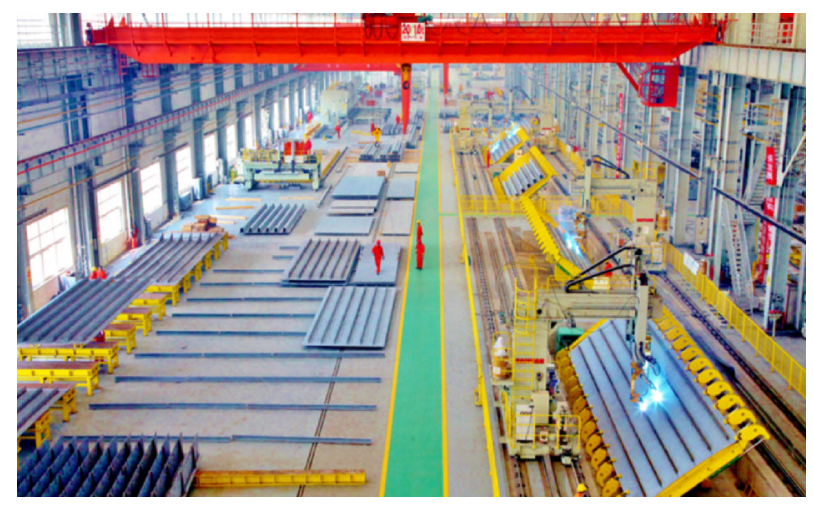

Fig. 5 Automatic production line of steel box beam plate unit of the bridge

automatic manufacturing of steel structure plate unit has been achieved. Compared with the traditional process, the production efficiency has increased by more than $300 \%$, and the quality has been remarkably improved. The automatic manufacturing of bridge steel structure accelerates the innovation of the technical and management level of steel bridge industry and promotes the transformation and industrial upgrading of bridge steel structure manufacturing industry in China.

\subsubsection{Assembly construction of the bridge structure}

The factory standardized production and the large-scale assembly construction are adopted in the bridge structure of the main project. The large-size prefabricated components are installed on the site using the large lifting equipment to reduce the risk of offshore construction and ensure construction quality and duration.

To satisfy the requirements of flood control and water resistance rate of the Pearl River Estuary, 190 pier shafts of the non-navigable bridge (maximum lifting weight is approximately $3200 \mathrm{t}$ ) are precast with concrete. They are transported to the construction site using a large-scale floating crane and all buried in depth of $8 \mathrm{~m}$ to $15 \mathrm{~m}$ below the seabed surface. This process is the first in the construction of bridge locally and internationally. Through the innovative construction methods, such as the new type of capsule for GINA water sealing belt and the dry construction of steel cylinder cofferdam, the water sealing and environmental protection problems caused by the embedded platform are successfully solved.

The steel box girder and composite beam of bridge engineering are hoisted span by span in large section of the entire hole. The maximum lifting weight of the steel box girder is approximately $3600 \mathrm{t}$. The navigable bridge steel towers of the Estuary Sea Bridge and Kyushu Bridge are completed by the entire hoisting construction. The construction environment and hoisting in the open sea are extremely difficult.

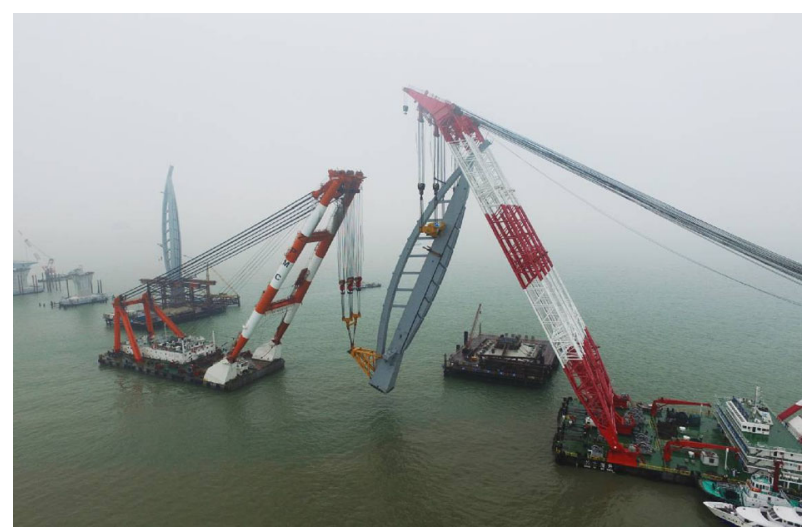

Fig. 6 Assembly construction of bridge structure

2.3 Research and development of new materials and equipment

A series of new materials and members (such as $75 \mathrm{~mm}$ prestressed steel bar, 120 year $\Omega$ rubber water stop, high damping rubber isolation bearings, tuned mass damper, stainless steel bar, and supporting system) is developed and used. Independent production is achieved, and foreign technical barriers are overcome. A number of core equipment of the tunnel foundation construction (including deep-water gravel-leveling ship, eight-hammer linkage large-scale vibration sinking system, multi-head foundation trench dredging vessel of deep water automatic positioning, and deep water unmanned docking system) have been independently developed. The steel-bridge deck-blasting machine is introduced and adopted for reference from the shipbuilding industry. The automatic spraying equipment of the waterproof layer is developed for the first time. The establishment of the world-leading pavement aggregate factory is promoted, the lean production of the dedicated aggregate materials for the bridge deck pavement is realized, and the problems that restrict the quality of the bridge deck pavement are solved.

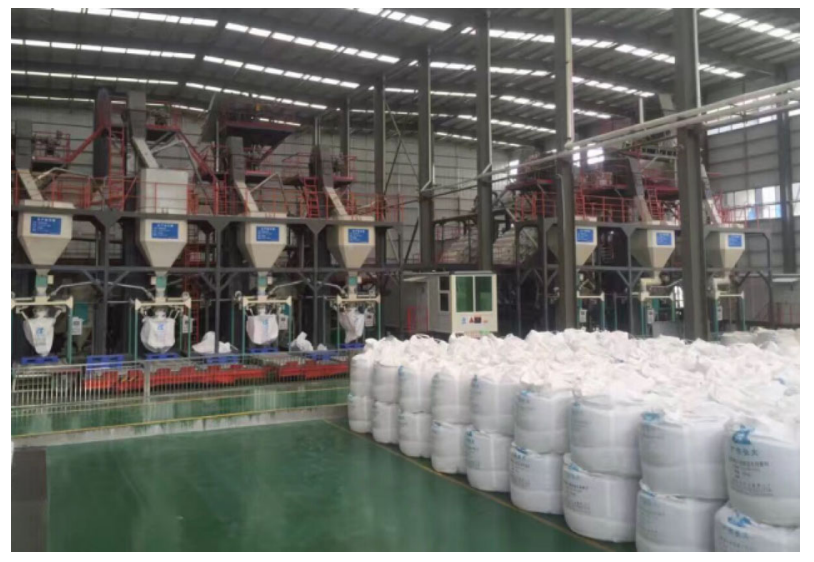

Fig. 7 Leading international aggregate factory dedicated for steel bridge decks 


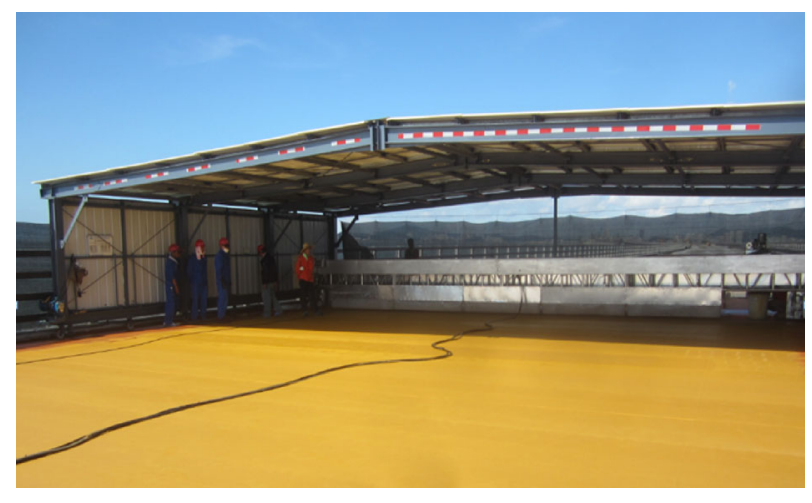

Fig. 8 Automatic spraying construction of waterproof bonding layer of steel bridge deck

\section{Innovation of project management}

The Hong Kong-Zhuhai-Macao Bridge is a super-large project with complex and giant system. The planning documents of the project management have been formulated, and the construction target, concept, and management model of the project have been determined at the feasible stage. The project management is guided by toplevel designs.

In view of the particularity of the co-construction and management of Guangdong, Hong Kong and Macao and based on the existing laws and regulations, the decisionmaking mechanism for the co-construction and management of the three local governments and the operation and management platform of the three places are established. A three-level organizational structure of "task force-three prefectural party committee-project legal person" is adopted in the construction management. Meanwhile, the bridge technical expert group, which is headed by the transportation department, is established in providing consultation and technical support to demonstrate major scheme and treatment measures of major engineering problems in the bridge construction process. The legal counsels provide the legal services in the entire process from the preliminary demonstration stage to the construction and operation periods of the project. Meanwhile, the design and construction consulting consortium composed of the well-known local and international consulting corporations provide the consultation service in the entire process of drawing design and construction. Thus, the project construction in all directions is supported. The bridge involves numerous new standards, processes, technologies, and equipment. The monographic studies on offshore engineering construction quota have been conducted under the strong support of the industry authorities. The research results show the basic data and reference for the establishment of national offshore engineering quota standard under the current condition of the standard lacunary of the national transportation engineering quota, which provides an important basis for the reasonable determination of project cost. The authority is responsible for the "construction, management, and maintenance" of the main engineering of the bridge. In view of this characteristic, the authority has creatively proposed an operation and preparation principle of "unchanged basic system, gradual superposition of functions, and timely and dynamic adjustment." The planning and development of the human resource system in the project construction and operation preparation has also been comprehensively considered to maximize the team stability during the construction period. Therefore, a solid foundation has been formed for the smooth development during the operation period.

In the implementation of each sub-project, the boundary conditions (such as different elements and environments), are identified, and a unique management strategy is formed. For instance, the design-build delivery management method is adopted in island tunnel engineering, a large-section construction contract concept is promoted in bridge engineering, and the general contracting mode of systematic integration is used in traffic engineering. These approaches provide advantages of market resources, embody the application and development of the engineering philosophy of "epistemology-methodologypractice," establish an efficient project management system, and effectively ensure the implementation of the project goals.

\section{Conclusions}

With the completion of the main project, the construction of Hong Kong-Zhuhai--Macao Bridge has entered a decisive stage. Through scientific organization, careful design, fine construction, and collective efforts, the bridge construction strives to combine the advanced world-class technology with the traditional artisan spirit. This construction will eventually become a high-quality and model engineering and a legacy project with inherent quality and function. 